\title{
PARQUES URBANOS, POPULAÇÃO E EXCLUSÃO EM SÃO PAULO
}

Recebido em: $31 / 01 / 2012$

Aceito em: 03/06/2012

\author{
Brenno Vitorino Costa ${ }^{1}$ \\ Luiz Octávio de Lima Camargo 2
}

Universidade Anhembi Morumbi

São Paulo - SP - Brasil

RESUMO: O artigo apresenta uma pesquisa documental sobre a distribuição dos parques urbanos municipais na cidade de São Paulo, relacionando essa distribuição com as áreas de inclusão e exclusão do município. Preliminarmente, buscou-se contextualizar as noções de áreas verdes, desde os primeiros surgidos no século XIX, sua gênese, os valores que presidiram à sua concepção, tipologia e parâmetros urbanísticos de inserção no espaço urbano. Neste estudo, ainda parcial, após um levantamento de dados de população e das áreas verdes inseridas em parques municipais, pôde-se constatar que a atual oferta destes equipamentos não atende às necessidades da população e que a exclusão no acesso ao lazer se dá não apenas pelas condições socioeconômicas de boa parte dos moradores, mas também pela má distribuição das áreas verdes, especialmente nos bairros periféricos.

PALAVRAS-CHAVE: Atividades de Lazer. Áreas Verdes. População.

\section{URBAN PARKS, POPULATION AND EXCLUSION IN SÃO PAULO}

ABSTRACT: This paper presents a documentary research on the distribution of urban municipal parks in the city of São Paulo, relating this distribution to the areas of inclusion and exclusion of the municipality. Preliminarily, we sought to contextualize the concepts of green areas, arising from the early nineteenth century, their type and their inclusion in desirable urban space. In this study still partial, after analyzing some population data and city parks' areas, it was found that the current supply of parks in Sao Paulo does not meet the needs of the population, both in terms of area and spatial distribution, especially in the suburbs.

KEYWORDS: Leisure Activities. Green Areas. Population.

\footnotetext{
${ }^{1}$ Mestrando em Hospitalidade pela Universidade Anhembi Morumbi e Especialista em Ecoturismo pelo SENAC-SP. Professor do curso de Tecnologia em Gestão de Turismo do Instituto Federal de São Paulo

${ }^{2}$ Docente do Programa de Mestrado em Hospitalidade da Universidade Anhembi Morumbi - São Paulo e do Bacharelado em Lazer e Turismo da EACH-USP
} 


\section{Introdução}

Os parques urbanos nasceram no século XIX sob o efeito das condições nas quais as cidades modernas se implantaram sobre os escombros da cidade medieval. Resumindo ao que interessa a este artigo, podem ser destacados dois contextos: em primeiro lugar, a consciência do impacto da falta de higiene sobre a saúde da população, mormente após as descobertas de Pasteur e, de outro, o duro cotidiano das nascentes classes operárias.

Ao longo do tempo, os parques ganharam visibilidade e importância, tornandose mesmo atrativos turísticos e referências de cidades. Daí que o tema foi rapidamente associado ao planejamento urbano, sempre atribuindo ao poder público o papel de protagonista. No Brasil, por exemplo, ao definir o lazer como um dos direitos sociais da população, o artigo $6^{0}$ da Constituição Federal evidencia o papel do poder público no provimento de espaços para prática do lazer (BRASIL, 1988). Embora não seja o único responsável pela oferta de opções de lazer, o Estado tem o dever e condições privilegiadas para propor e decidir sobre alternativas de uso de espaços urbanos.

Em uma metrópole como São Paulo, o desafio de prover aos cidadãos opções públicas de lazer é enorme. Dentre os equipamentos do município figuram praças, jardins públicos, parques urbanos, museus, centros culturais, centros educacionais e esportivos, entre outros. Infelizmente, esses equipamentos não se mostram suficientes para atender a seu vasto contingente populacional. Ademais, boa parte das estatísticas de áreas verdes inclui canteiros centrais, de avenidas, de marginais, sem contar as que foram inutilizadas pelas muitas intervenções no trânsito. A situação mostra-se ainda mais crítica ao se considerar às desigualdades entre os diferentes bairros do município, 
refletidas não somente nas condições socioeconômicas de seus moradores, mas também na oferta de serviços públicos.

O objetivo desta reflexão é contribuir para o entendimento da distribuição de parques urbanos municipais na cidade de São Paulo como um campo adicional da exclusão social. Para ilustrar essa relação entre acesso a parques municipais e lazer trazem-se aqui as primeiras análises sobre a quantidade de parques municipais e a exclusão.

Entre as referências metodológicas devem ser consideradas: (a) pesquisa bibliográfica sobre a temática de parques urbanos, mormente no campo do urbanismo; (b) levantamento dos parques urbanos na cidade de São Paulo; e (c) pesquisa documental através do Mapa da Exclusão/Inclusão Social da Cidade de São Paulo, parte de um projeto de pesquisa coordenado por Aldaísa Sposati que identifica relações de exclusão dentro da referência geográfica (SÃO PAULO, 2002). Os dados sobre as áreas verdes foram levantados junto aos órgãos municipais, notadamente a Secretaria de Meio Ambiente. Esta reflexão beneficiou-se também da pesquisa de Bartalini (1999) sobre a história e a evolução das áreas verdes do município de São Paulo.

Enquanto arrazoado, optou-se por iniciar com uma reflexão sobre as diferentes modalidades de áreas verdes urbanas e as estratégias do urbanismo para conceber sua distribuição. Em seguida, vêm os temas do crescimento desordenado e de como tal fenômeno desembocou numa nova forma de exclusão social, a do acesso às áreas verdes, e uma nova categoria da exclusão, aquela que poderia para efeito desta discussão chamar-se de geográfica, que mantém uma relativa autonomia em face da categoria de exclusão socioeconômica. 


\section{Parques urbanos como espaços de lazer}

Os parques urbanos, vistos retrospectivamente, surgiram da necessidade de dotar as cidades de espaços adequados para atender à demanda social pelo lazer e para contrapor-se ao ambiente urbano (MACEDO; SAKATA, 2010, p.7). Os primeiros datam do século XIX, coincidindo com o momento de consolidação das sociedades industriais. Não por coincidência, a constituição do lazer enquanto campo de estudo, no final do século XIX data exatamente da mesma época em que as primeiras conquistas trabalhistas garantiam às pessoas mais tempo livre, tempo esse ocupado na sua quase totalidade como tempo de lazer..

Para Macedo e Sakata (2010, p.14), parque urbano é

[...] todo espaço de uso público destinado à recreação de massa, qualquer que seja seu tipo, capaz de incorporar intenções de conservação e cuja estrutura morfológica é auto-suficiente, isto é, não é diretamente influenciada em sua configuração por nenhuma estrutura constituída em seu entorno.

Não foram, contudo apenas as emergentes necessidades de lazer na cidade oitocentista ocidental que estão na origem dos parques. Ao contrário do que possa parecer, os parques não nasceram movidos apenas por essas necessidades de lazer da população e sim pelos novos ideais de higiene que nascem no século XIX, consubstanciadas no que se denominou de movimento higienista. Trata-se, pois, de uma dupla orientação: do higienismo e do lazer.

O higienismo ou movimento higienista, como bem notou Vigarello (1993), designa uma corrente de pensamento iniciada no meio do século XIX que se baseia nas descobertas de Louis Pasteur sobre o papel das bactérias e micróbios na contaminação humana e doenças daí derivadas. Os cuidados com o corpo são objeto de práticas novas com o corpo, atenção à alimentação, aos maus odores. Nascem as primeiras iniciativas 
de saneamento da água, dos dejetos urbanos, e, também do ar. A necessidade de espaços livres que dispersassem os odores urbanos, assim, está na origem das áreas verdes das cidades, que a população transformou em espaço de lazer.

$\mathrm{Na}$ Inglaterra, surgem as primeiras teorias e práticas sobre a implantação de parques. O Hyde Park ${ }^{3}$, terreno de caça da monarquia, foi paulatinamente aberto e entregue aos moradores de Londres, no início do séc.XIX, medida que Napoleão III repetiu em seguida na França, ao também doar também, em 1850, seu território de caça para a implantação do Bois de Boulogne ${ }^{4}$. Em 1852, o Central Park ${ }^{5}$ de Nova Iorque é o primeiro a ser projetado e implantado, já considerando, diferentemente dos anteriores, a perspectiva do lazer e do higienismo.

Assim, se o pensamento higienista constituía a filosofia que orientou as primeiras iniciativas de áreas verdes, o uso dessas áreas para o lazer aconteceu de imediato pela necessidade sentida pelos cidadãos de passear com a família, de fazer piqueniques, de folguedos, etc. Os parques nascem assim de uma curiosa dicotomia entre uma filosofia higienista oficial e o lazer efetivamente buscado pela população, o que ocorreu também no Brasil. Segundo Gomes e Melo (2003, p.26), os parques infantis implantados na década de 1930 por Mário de Andrade, então Secretário de Educação e Recreação da Prefeitura da cidade de São Paulo, mencionavam a filosofia de despertar nas novas gerações o gosto e criar o hábito de empregar seus lazeres em atividades saudáveis de grande alcance moral e higiênico.

Faria (1999, p.9) também menciona nas ações dessa Secretaria, na década de 1930, em São Paulo, essa duplicidade de objetivos "entre a ênfase no aspecto lúdico,

\footnotetext{
${ }^{3}$ Parque de $2,5 \mathrm{~km}^{2}$ (incluindo parques adjacentes) no centro de Londres

${ }_{5}^{4}$ Parque de $8,5 \mathrm{~km}^{2}$ na região noroeste de Paris, ainda hoje o mais famoso daquela cidade

${ }^{5}$ Parque de 3,4 $\mathrm{km}^{2}$ no centro de Manhattan projetado por Frederic Law Olmstead e implantado em região então alagadiça e insalubre
} 
nas brincadeiras, nos jogos tradicionais infantis e os objetivos oficiais de educação moral, higiênica e estética”.

Frederick Law Olmsted, idealizador do Central Park, defendia que os parques urbanos constituem um ponto de encontro para todos os cidadãos (MACEDO; SAKATA, 2010). Nesse sentido, desempenham um importante papel de sociabilização nas cidades ao ampliar o olhar de seus visitantes, evocar idéias de abertura e liberdade, associadas a uma memória pessoal e coletiva repleta de emoção e afetividade (SCHREIBER, 1997, p.150).

De qualquer forma, as cidades passam a ter nas áreas verdes uma alternativa de passeio público diferente daquela que se realizava no nascente setor econômico privado do entretenimento - restaurantes, confeitarias, teatros, os primeiros parques de diversões, dentre outros - restrita às pessoas com maior poder aquisitivo. Nasce, assim, uma noção de parque público associada a áreas verdes públicas, que teve na Inglaterra não apenas o seu pioneirismo como o caráter social que lhes foi atribuído. Conforme Bartalini (1999, p.6):

O pioneirismo inglês não se limitou à adaptação do jardim paisagístico (...) no atual parque público urbano. Tão importante quanto a isto foi o caráter social que a Inglaterra imprimiu às áreas verdes, transformandoas em "parques públicos".

A perspectiva social que acompanhou seu nascimento deriva, como se vê, da mesma dicotomia acima lembrada que coloca o divertimento sob a égide da saúde pública e da recuperação da energia para o trabalho. Como diz Panzini (1993, p.149).

Aquele espaço urbano usado pelas classes abastadas para realizar o rito social de encontrar-se e exibir-se, lugar prazeroso onde a vegetação tem a função cenográfica de refinar e refrescar o lugar adquire na Inglaterra um caráter utilitarista; ao ambiente natural da cidade é atribuída a função de prover e restaurar a função psíquica do trabalhador, colocada numa profunda crise pelas modalidades de vida e trabalho na cidade da Revolução Industrial. 
Muito haveria que se escrever aqui sobre as ideologias subjacentes a tais iniciativas de cujo confronto surgem não apenas os parques, como outras iniciativas tais como as associações voluntárias de cunho filantrópico, que, de um lado, refletiam a tentativa de controle social da população operária e dos lazeres perigosos tais como o álcool, os jogos de azar, quando não a ociosidade pura e simples e, de outro, uma "consciência culpada" em relação às desumanas condições de vida dessa população (PRONOVOST, 1983).

De qualquer forma, aos poucos o urbanismo posiciona-se como principal protagonista na criação de áreas verdes públicas em geral. O principal documento a consolidar o pensamento urbanístico vigente no início do século $\mathrm{XX}$ foi a Carta de Atenas, de 1933, que já colocava o problema nos seguintes termos:

O núcleo das cidades antigas, cercado por muralhas militares, era em geral comprimido e cheio de construções comprimidas e privadas de espaço, mas, em compensação, ultrapassada a porta da muralha, os espaços verdes eram imediatamente acessíveis. Ao longo dos séculos, foram sendo acrescentados anéis urbanos, substituindo a vegetação pela pedra e destruindo as superfícies verdes, pulmões da cidade ( $2^{\mathrm{a}}$ parte, item 9).

Forçoso é destacar ainda que a mesma Carta colocava a necessidade de áreas verdes livres sob a égide de outro problema que também faz parte do conjunto de necessidades urbanas, o do lazer, ao lado da habitação, a circulação e o trabalho.

(Os espaços verdes e livres) podem ser os prolongamentos diretos ou indiretos da moradia; diretos, se cercam a própria habitação; indiretos, se concentrados em algumas grandes superfícies, não tão próximas. Em ambos os casos, sua destinação será a mesma: acolher as atividades coletivas da juventude, propiciar um espaço favorável às distrações, aos passeios ou aos jogos das horas de lazer (item 30 - capítulo Lazer).

Hoje, a necessidade de áreas verdes em áreas urbanas vem sendo a preocupação de urbanistas, que têm, nos Planos Diretores das municipalidades, a oportunidade de planejá-las. Desnecessário é acrescentar que se vêem, de um lado, uma progressiva 
conscientização da população sobre a necessidade de áreas livres e verdes e iniciativas do poder público de ampliação e revitalização, e, de outro, a voracidade do trânsito que engole áreas que, se não serviam à recreação, cumpriam ao menos as funções higiênica e estética.

\section{Tipologia e inserção de áreas verdes e livres no espaço urbano}

Sempre que se inaugura uma nova área verde na cidade de São Paulo ou, ao contrário, quando alguma delas é ameaçada pela expansão urbana, a mídia local faz menção a um suposto critério da Organização Mundial da Saúde que estabelece uma média de $12 \mathrm{~m}^{2}$ de área verde por habitante. Ainda que esse critério faça sucesso na mídia ou exatamente por isso, deve-se mostrar seu equívoco. Há diferentes tipos de áreas verdes com características diferentes tanto do ponto vista como do atendimento

Na década de 1970, em especial na França, Coronio e Muret (1976, p.74-80) diferentes documentos trataram da questão da quantidade de áreas verdes/livres por habitante. A tônica desses estudos foi à consideração segundo a qual, mais do que a área por habitante, importava a questão da acessibilidade dos usuários, notadamente do ponto de vista da distância entre moradia e o tipo de parque buscado, ou seja, o raio de influência de um parque e sua função social.

- Áreas de condomínio e de vizinhança, de área reduzida para a parcela da população de mobilidade urbana reduzida, como bebês e crianças, idosos e deficientes em geral, notadamente para espairecer ou tomar sol, dentre outros.

- Áreas de bairro que, além de servir à vizinhança como os anteriores, destina-se a jovens e adultos em busca de exercitar-se fisicamente, participar de pequenos eventos e programações, etc. 
- Parques urbanos, que, além de cumprir as funções dos equipamentos anteriores, destinam-se a famílias e casais, sobretudo em fins de semana, interessadas no convívio em meio a uma natureza domesticada.

- Parques metropolitanos necessários, sobretudo nas áreas conturbadas, mais prejudicadas pela monotonia da paisagem, para contato com a natureza virgem ${ }^{6}$.

\section{TABELA 1}

\section{Classificação dos espaços verdes segundo o tipo e raio de influência}

\begin{tabular}{|c|c|c|}
\hline Localização & Tipos de instalações & Raio de influência \\
\hline $\begin{array}{l}\text { Condomínios } \quad\left(\begin{array}{ll}200 & \text { a } \\
500 \text { unidades } & \end{array}\right. \\
\end{array}$ & $\begin{array}{l}\text { Área de jogos e brincadeiras infantis } \\
\text { Áreas de descanso para idosos } \\
\text { Gramados decorativos }\end{array}$ & 30 a $100 \mathrm{~m}$ \\
\hline $\begin{array}{l}\text { Vizinhança } \\
(1.000 \mathrm{a} \quad 1.200 \\
\text { unidades habitacionais }\end{array}$ & $\begin{array}{l}\text { Parques infantis } \\
\text { Áreas de jogos livres } \\
\text { Jardins e praças públicas } \\
\text { Pistas de caminhada }\end{array}$ & 250 a $300 \mathrm{~m}$ \\
\hline $\begin{array}{l}\text { Bairro } \\
(4.000 \quad \text { a } \\
\text { unidades } \\
\text { habitacionais) }\end{array}$ & $\begin{array}{l}\text { Jardins públicos } \\
\text { Áreas de jogos e de passeios } \\
\text { Áreas esportivas } \\
\text { Pistas de caminhada } \\
\text { Parques de bairro }\end{array}$ & 500 a $800 \mathrm{~m}$ \\
\hline $\begin{array}{l}\text { Cidade } \\
\text { (cada } 500 \quad \text { mil } \\
\text { habitantes) }\end{array}$ & $\begin{array}{l}\text { Parques verdes (natureza domesticada) } \\
\text { Parques de atrações } \\
\text { Equipamentos esportivos polivalentes } \\
\text { Jardins botânicos } \\
\text { Zoológicos } \\
\text { Parques urbanos } \\
\text { Parques metropolitanos (natureza intocada) } \\
\text { Hipódromos } \\
\text { Áreas de lazer ao ar livre } \\
\text { Florestas abertas ao passeio } \\
\text { Áreas de camping e caravaning }\end{array}$ & Acima de $2.000 \mathrm{~m}$ \\
\hline
\end{tabular}

Nas estatísticas municipais, não há distinção entre esses tipos de áreas verdes. Ademais, incluem canteiros das avenidas, áreas livres inacessíveis, como a que margeiam os rios e córregos da cidade.

\footnotetext{
${ }^{6}$ Aqui não serão mencionados os Parques Estaduais, não apenas por situarem-se fora dos limites da cidade, bem como por não serem inteiramente abertos à freqüência da população.
} 


\section{Crescimento populacional e áreas verdes em São Paulo}

Qual foi o impacto do crescimento populacional em São Paulo sobre suas áreas verdes? A hipótese mais óbvia e, sem dúvida, a mais importante privilegia o crescimento desmesurado da cidade com todas as suas seqüelas, inclusive aquela que aqui é tratada, a de uma cidade que engole seus espaços livre. Há uma segunda, pouco lembrada, que é a tardia consciência sobre a importância das áreas verdes. Ou seja, a própria população apenas recentemente vem se manifestando.

O município de São Paulo configura um caso singular de metropolização em poucas décadas. Em pouco mais de cem anos - de uma Vila no final do século XIX até os dias atuais - a cidade transformou-se na quarta cidade mais populosa do mundo, com 11.057.629 milhões de habitantes em 1.509 km² (SÃO PAULO, 2011).

Vários fatores históricos podem explicar o rápido crescimento populacional do município (SÃO PAULO, 2007). Num primeiro momento, a partir de 1870, São Paulo se consolida como local de desembarque de imigrantes europeus que iriam trabalhar nas lavouras de café do interior, além de ser ponto de passagem da produção cafeeira ao Porto de Santos. A riqueza gerada pela exportação do café viabilizaria, num segundo momento, a industrialização no município, atraindo outra leva enorme de pessoas, desta vez de outras partes do Brasil, para trabalhar nas fábricas, desde o início do século XX, atingindo o auge após os anos 1960.

Após os anos 1980, São Paulo passa a concentrar suas principais atividades econômicas no setor terciário, com a saída das empresas para outros municípios. A taxa de crescimento populacional diminui, mas a cidade já não escondia a falta de planejamento em sua infraestrutura básica, inclusive de áreas verdes (BARTALINI, 1999, p.22-37) e mostrava a impossibilidade de o poder público prover mínimas 
condições de moradia, saúde, educação e lazer, entre outros, para o contingente humano que se instalara no município.

Durante a década de 1990, somente os distritos situados nos extremos da cidade, notadamente os limítrofes com outros municípios da região metropolitana, continuaram a ter crescimento vegetativo positivo. O prolongamento da desconcentração industrial, o alto custo de vida no município e a expansão das atividades terciárias no centro podem ser citados como fatores para o aumento do contingente populacional nas áreas periféricas de São Paulo (SÃO PAULO, 2007).

Por que o nascimento de uma tardia consciência sobre a necessidade de áreas verdes em São Paulo e no resto do país? Não se deve esquecer que o Parque Ibirapuera, hoje o principal ícone do passeio público paulistano no início da década de 1970 ainda tinha uma freqüência diminuta, com a população assistindo passivamente ao processo de ocupação para outros fins de nesgas fronteiriças que diminuíram consideravelmente sua extensão. Apenas após o advento da prática da caminhada, da corrida, a freqüência começou a aumentar a ponto de o parque estar hoje, em sábados e domingos, inteiramente ocupado pela população.

Essa tardia consciência nunca foi generalizada. As elites sociais e culturais já estavam atentas a essa necessidade (vide abaixo). Contudo, se os migrantes europeus tiveram importante papel no processo de desenvolvimento cultural da cidade, deve-se lembrar também que a infraestrutura da população urbana paulistana é constituída de migrantes rurais. A integração desses migrantes na Capital sempre foi delicada (CÂNDIDO, 1964; FLUSSER, 1998). Tudo se passa como se, com quase quatro séculos de atraso, esses migrantes, tal como os rurais medievais, fossem confrontados às regras implícitas no processo civilizador, de que fala Elias (1994). Pode-se colocar, ao 
menos como hipótese, que esse aumento migratório, mormente das zonas rurais brasileiras, deriva em parte da incúria do poder público. Efetivamente, essa incúria é gritante e as periferias dispõem de menor número de espaços verdes de proximidade que, aparentemente, não foram considerados necessários por ocasião do planejamento dos loteamentos. Empreendedores e habitantes, ao que tudo indica, talvez não os julgassem necessários e o poder público não se fez presente para fiscalizar os novos assentamentos urbanos que surgiam a todo o momento e exigir o espaço livre necessário à prática de lazer.

\section{Urbanização e exclusão}

Até 1930, a organização urbana no Brasil foi uma herança direta da colonização, acompanhado as atividades econômicas e a localização do poder políticoadministrativo. Dessa forma, as cidades eram resultantes da instalação dos serviços do governo e das atividades econômicas, priorizando sempre a exportação (SANTOS, 1967).

A partir da década de 1940, ocorrem mudanças significativas na organização urbana brasileira, causadas por três razões principais: o aumento acelerado da população, formas induzidas de desenvolvimento industrial mundial e crescimento industrial do país (SANTOS, 1967). A industrialização concentrou nas metrópoles as oportunidades de trabalho, e esse contingente populacional deslocaram-se a ela em busca de oportunidades de trabalho e renda. Em 1940, a população urbana correspondia a $36,16 \%$ da população brasileira, em $1960,45 \%$ e hoje soma $80 \%$ da população geral (SANTOS, 1967; IBGE, 2010). 
Esse processo, principalmente nas grandes metrópoles, produziu um cenário desigual, em que o acesso à moradia, a serviços públicos - de educação, lazer, saúde, transportes, etc. - e ao emprego são concentrados em determinados bairros. Trata-se do que Kowarick (2000, p. 22), define como espoliação urbana, isto é,

[...] a somatória de extorsões que se opera pela inexistência ou precariedade de serviços de consumo coletivos, que juntamente ao acesso à terra e à moradia apresentam-se como socialmente necessários para a reprodução dos trabalhadores e aguçam ainda mais a dilapidação decorrente da exploração do trabalho ou, o que é pior, da falta desta.

Ao contrário do que se deveria esperar, o investimento público prioriza as áreas em que vivem e trabalham grupos de renda média e alta, ocasionando um processo de contradições urbanas, uma vez que o investimento público em bens de consumo coletivos não visa à grande massa de trabalhadores (KOWARICK, 2000).

Essa ausência ou precariedade de políticas sociais, somadas ao nível de qualificação profissional dos cidadãos, a fatores biológicos como sexo e idade, aos impactos do retrocesso da economia e ao descompasso entre a remuneração e a produtividade do trabalho produz a exclusão social (KOWARICK, 2000).

Na cidade de São Paulo, a distribuição dos equipamentos de lazer evidencia a exclusão social, como, aliás, ocorre na quase totalidade de cidades brasileiras (SILVA; NUNES, 2009). Para Botelho (2003), por exemplo, a distribuição dos equipamentos culturais revela uma cidade desequilibrada, não só em relação ao espaço, mas à disponibilidade de tempo livre para usufruto do lazer. Nos itens seguintes, procura-se refletir sobre como isso se manifesta, especificamente, em relação aos parques urbanos municipais do município.

Para que isso se concretize, os parques urbanos devem estar em locais de fácil acesso e, numa metrópole com as dimensões de São Paulo, devem atender a milhares de 
visitantes diários em suas diferentes regiões. É de se esperar, portanto, que haja uma rede de parques que possibilite não apenas a escolha entre vários, mas que se possa usufruir o lazer numa distância digna a partir da própria residência.

\section{Parques urbanos em São Paulo}

A sétima década do século XIX e as três primeiras décadas do século XX viram a criação de apenas duas áreas verdes: o Jardim da Luz e o Parque da Várzea do Carmo, que podem ser consideradas as mais importantes intervenções do poder municipal no suprimento de áreas verdes de recreação até a inauguração do Parque Ibirapuera, já em 1954. Os parques municipais criados nesse meio tempo (Trianon, Buenos Aires e Aclimação) saíram do papel muito mais pela participação da iniciativa privada da época que pelo esforço da prefeitura. De qualquer forma, o lazer da população, até meados dos anos 1950, estava nas várzeas dos rios, onde ocorriam banhos e partidas de futebol, ou nas ruas, sem a necessidade de uma intervenção real da prefeitura (BARTALINI, 1999).

Ainda que vários projetos urbanos destacassem a necessidade de áreas verdes para a cidade, as iniciativas para o lazer em parques públicos municipais continuavam conservadoras. Dos anos 1930 até meados da década de 1960, a população de São Paulo multiplicou-se por seis, e a área urbanizada cresceu quatro vezes, sem que houvesse qualquer plano para áreas verdes de recreação. Embora existisse uma obrigação legal de se doar uma porcentagem da área dos loteamentos para áreas verdes, a prefeitura não fiscalizava a constituição desenfreada de loteamentos clandestinos (BARTALINI, 1999).

Na década de 1970, a prefeitura tomou iniciativas de aumentar a oferta de áreas verdes, mas não havia um plano específico. Aproveitavam-se oportunidades ou seguiase a determinação pessoal do prefeito da época. As áreas, em geral, eram remanescentes 
de antigas chácaras ou congregações religiosas, já extensamente arborizadas e que não precisavam de mais do que alguns equipamentos como brinquedos e quadras poliesportivas para o uso recreativo (BARTALINI, 1999).

Depois da década de 1970, outro hiato se formou na criação de parques, interrompido com a criação de vários pequenos parques municipais entre 1989 e 1992. A cidade teve apenas algumas iniciativas esparsas até a criação do projeto "100 parques para São Paulo", em 2008. O projeto tem como meta um total de 100 parques implantados até 2012, numa área total de 50 milhões de metros quadrados. Se a meta se concretizar no prazo estabelecido, cada morador de São Paulo terá à sua disposição, teoricamente, $4 \mathrm{~m}^{2}$ de área verde em parques municipais.

\section{Análise dos dados: os parques municipais de São Paulo e a população}

O interesse principal da adoção da matriz de exclusão de Sposati deve-se ao fato de privilegiar a inserção dessas áreas no espaço urbano. Com isso, assume-se o ponto de vista segundo qual a exclusão não acontece apenas do ponto de vista socioeconômico, de gênero, de idade, de escolaridade e de acessibilidade a pessoas deficientes. $\mathrm{Na}$ verdade, o mesmo estudo de Sposati já trabalha nessa perspectiva de demonstraram que a exclusão, aqui consideradas as áreas verdes de lazer, é maior sob este critério geográfico que os demais, na medida em que de certa forma os engloba. Um empresário morando na periferia da Região Metropolitana tem menos acesso aos bens culturais da cidade do que um indivíduo pobre que mora em bairros culturalmente mais ativos.

A TAB. 2 apresenta a quantidade de parques por subprefeitura do município, a área compreendida por esses equipamentos, a população por subprefeitura e o índice de área verde por pessoa em parques urbanos municipais. 
TABELA 2

Relação entre área em parques municipais e população por subprefeitura

\begin{tabular}{|c|c|c|c|c|}
\hline Subprefeitura & Parques & Área $\left(\mathrm{m}^{2}\right)$ & População & $\left(\mathrm{m}^{2} / \mathrm{hab}\right)$ \\
\hline Aricanduva & 1 & 70000 & 253855 & 0,28 \\
\hline Butantã & 7 & 1433288 & 383061 & 3,74 \\
\hline Campo Limpo & 4 & 440332 & 590602 & 0,75 \\
\hline Capela do Socorro & 2 & 100643 & 696941 & 0,14 \\
\hline Casa Verde & 0 & 0 & 313666 & 0,00 \\
\hline Cidade Ademar & 0 & 0 & 406871 & 0,00 \\
\hline Cidade Tiradentes & 3 & 895200 & 219868 & 4,07 \\
\hline Ermelino Matarazzo & 1 & 5000 & 210263 & 0,02 \\
\hline Freguesia/Brasilândia & 0 & 0 & 418170 & 0,00 \\
\hline Guaianases & 0 & 0 & 296509 & 0,00 \\
\hline Ipiranga & 1 & 161300 & 425451 & 0,38 \\
\hline Itaim Paulista & 4 & 158738 & 403512 & 0,39 \\
\hline Itaquera & 2 & 1533000 & 528543 & 2,90 \\
\hline Jabaquara & 2 & 46300 & 212504 & 0,22 \\
\hline Jaçanã/Tremembé & 0 & 0 & 278567 & 0,00 \\
\hline Lapa & 2 & 112186 & 265537 & 0,42 \\
\hline M'Boi Mirim & 0 & 0 & 553384 & 0,00 \\
\hline Mooca & 1 & 97200 & 296184 & 0,33 \\
\hline Parelheiros & 1 & 16000 & 156392 & 0,10 \\
\hline Penha & 2 & 324400 & 472266 & 0,69 \\
\hline Perus & 1 & 9500000 & 138268 & 68,71 \\
\hline Pinheiros & 3 & 196000 & 257722 & 0,76 \\
\hline Pirituba & 7 & 578116 & 450297 & 1,28 \\
\hline Santana & 1 & 23700 & 303173 & 0,08 \\
\hline Santo Amaro & 2 & 68900 & 219659 & 0,31 \\
\hline São Mateus & 0 & 0 & 436195 & 0,00 \\
\hline São Miguel Paulista & 2 & 95600 & 414786 & 0,23 \\
\hline Sé & 3 & 250600 & 346512 & 0,72 \\
\hline Vila Maria & 3 & 224115 & 284494 & 0,79 \\
\hline Vila Mariana & 1 & 1584000 & 295719 & 5,36 \\
\hline Vila Prudente & 2 & 70000 & 528658 & 0,13 \\
\hline Total onde há parques & 58 & 17984618 & 8354267 & 2,15 \\
\hline Anhanguera & & & & \\
\hline (Perus) & 57 & 8484618 & 8215999 & 1,03 \\
\hline Total Geral & 58 & 17984618 & 11057629 & 1,63 \\
\hline
\end{tabular}

Deve-se atentar para o fato de um único Parque (Anhanguera) ser responsável por quase metade da área de São Paulo em parques municipais. Logo, o índice de $1,63 \mathrm{~m}^{2}$ é relativo e não foi ainda minimizado pelas áreas recentemente criadas, tendo apenas recuperado parcialmente o aumento da população durante o século XX. Nota-se 
ainda que sete (Casa Verde/Cachoeirinha, Cidade Ademar, Freguesia/Brasilândia, Guaianases, Jaçanã/Tremembé, M’Boi Mirim e São Mateus) das 31 subprefeituras não tem qualquer parque municipal em sua área, e nelas moram mais de 2,5 milhões de pessoas. Trata-se de áreas periféricas da cidade, com uma população majoritariamente de classes $\mathrm{C}$, D e E, ou seja, exatamente aquela que mais necessita de políticas sociais para o lazer. Isso não quer dizer que esses moradores estão alijados do contato com o verde, uma vez que as praças municipais, em sua maioria, não entram na conta das áreas verdes da cidade, e não se aborda, neste trabalho, a existência de espaços como os Clubes Escola.

A inexistência de parques municipais em sete subprefeituras e os baixíssimos índices de área verde por habitante em subprefeituras populosas como as de Campo Limpo, Capela do Socorro e Vila Prudente demonstram que há um processo histórico de exclusão - não apenas econômica, mas também do lazer - de grandes massas populacionais nos extremos da cidade de São Paulo.

Por outro lado, mesmo bairros centrais e tidos como privilegiados nos critérios de inclusão social não podem ser considerados supridos desse tipo de área verde. Nesse caso, como alguns são de ocupação mais antiga, a vegetação foi substituída pelas construções em concreto, impossibilitando ou dificultando, há décadas, o estabelecimento de novos parques urbanos.

Para ilustrar melhor essa relação entre acesso ao lazer através da quantidade de parques municipais e a exclusão, fez-se uso do "Mapa da Exclusão/Inclusão Social da Cidade de São Paulo", que é parte de um projeto de pesquisa (SÃO PAULO, 2002). 


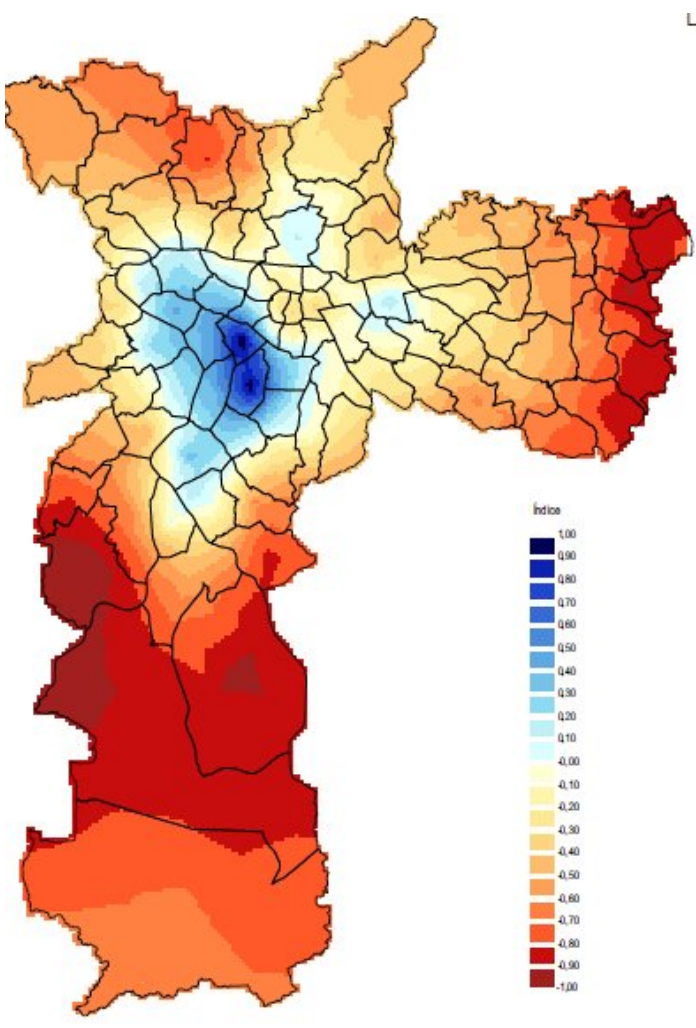

FIGURA 1 - Mapa da Exclusão - São Paulo Fonte: SÃO PAULO, 2002.

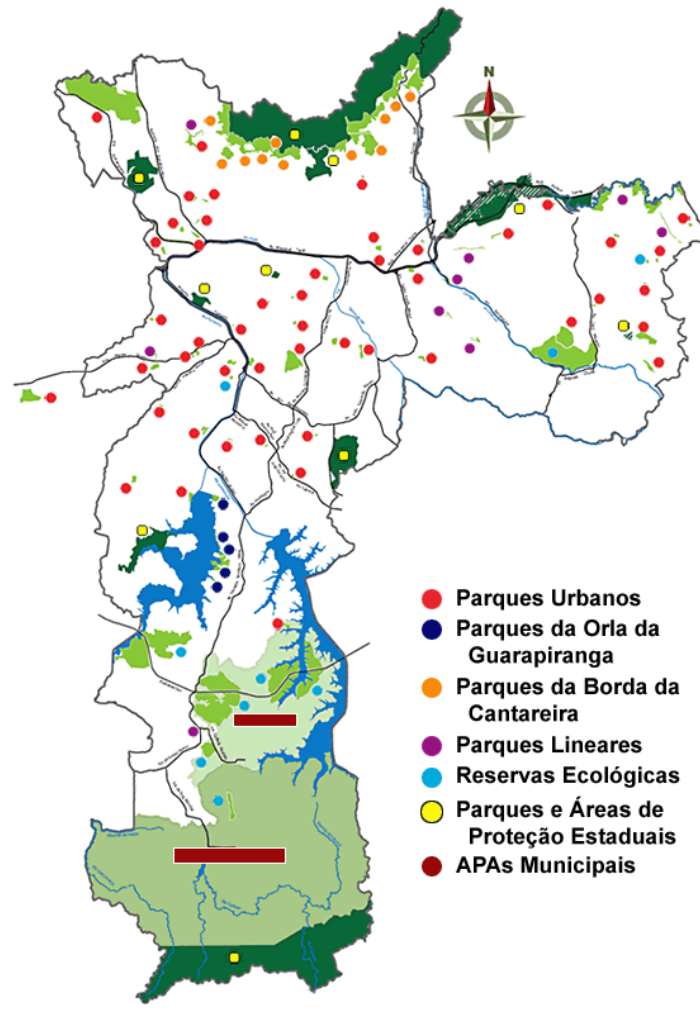

FIGURA 2 - Áreas verdes de São Paulo Fonte: SÃO PAULO, 2010.

O Mapa hierarquiza os 96 subdistritos municipais quanto ao grau de exclusão/inclusão social, com base em dados dos censos demográficos e de diversas estatísticas municipais. Para identificar a exclusão, criou-se um índice medido em quatro dimensões: autonomia (renda dos chefes de família e oferta de emprego); qualidade de vida (acesso a serviços básicos, densidade habitacional e conforto domiciliar); desenvolvimento humano (nível de escolaridade dos chefes de família, longevidade, mortalidade infantil e juvenil e violência), e equidade (grau de concentração das mulheres como chefes de família). A cada indicador foram atribuídas notas decimais positivas ou negativas, variando de -1 a 1 . 
Na FIG. 1 os tons azulados indicam a inclusão (notas positivas), e os que variam de amarelo a marrom, a exclusão. A FIG. 2, por sua vez, apresenta o mapa com as áreas verdes do município de São Paulo, em diversas categorias.

Nota-se que o maior número de parques urbanos (representados pelas bolinhas vermelhas da FIG. 2) está exatamente nas áreas em azul do Mapa da Exclusão, ou seja, atendem públicos de maior qualidade de vida, e onde de fato estão alguns dos bairros mais tradicionais e elitizados da cidade, como Jardins, Higienópolis e Moema. Nas demais áreas, os parques urbanos são raros.

É importante dizer que, nas áreas em que aparentemente há uma grande extensão de áreas verdes (extremos Norte e Sul), trata-se de unidades de conservação, em que a prática do lazer é proibida ou é restrita a pequenos espaços, não resolvendo o problema da exclusão que se verifica nestas áreas. Além disso, há algumas concentrações de parques recém-criados nas bordas da Serra da Cantareira (ao Norte, bolinhas laranja) e da Represa de Guarapiranga (bolinhas azul escuro), mas, em que pese o uso recreativo, fica claro no material da prefeitura (SÃO PAULO, 2010) que a função desses parques é a de criar uma "zona de amortecimento" entre Áreas de Preservação Permanente e a ocupação urbana.

Pior é perceber, ainda pela leitura dos materiais da prefeitura e de Whately (2008), que a expansão das áreas verdes tem muito mais relação com a redução das chamadas "ilhas de calor" e a adequação da cidade a acordos internacionais como o Protocolo de Kioto do que com a expansão da oferta de áreas verdes de lazer. Até mesmo a atração de investimentos é colocada como um motivo para a criação de parques! 
Hoje se instala uma perspectiva nova que é a da importância econômica dos parques como valor agregado a imóveis da vizinhança e à cidade. A pequena distância de um parque é fator valorizado na publicidade de prédios e edifícios, o que se reflete no aumento de seu IPTU. O problema (ignore-se por ora a ganância imobiliária que, infelizmente, está fora do objetivo deste texto) diz respeito à manutenção dos parques, que dispõem de verba exígua enquanto suas receitas (pontos de comércio licitados, cessão de espaços para publicidade) se perdem no erário público.

A transformação de um parque em Fundação é sem dúvida uma solução. Além de recursos do poder público poderia buscar e utilizar recursos adicionais. A idéia, também aqui válida para diferentes parques, já vem sendo objeto de duas iniciativas uma já implantada (Fundação Aaron Birman para o Parque Burle Marx) e outra, em estudo na Câmara Municipal, desde a década de 1980, a Fundação do Parque do Ibirapuera. No primeiro caso, a municipalidade não transfere recursos; transfere encargos de gestão, define diretrizes de gerenciamento e utilização e avalia resultados. A Prefeitura e a Secretaria do Verde e Meio Ambiente estabelece em conjunto com a Fundação metas de desenvolvimento e valorização do Parque, respeitadas as diretrizes do Plano Diretor e de seu regulamento.

Já no caso da Fundação do Parque do Ibirapuera, a Fundação ficaria subordinada ao executivo municipal, tendo no seu Conselho Curador alguns membros natos, como o Secretario Municipal de Cultura, o Secretário Municipal de Esportes, Lazer e Recreação, o Secretário Municipal de Serviços e Obras, o Secretário de Estado da Cultura, os Presidentes da Comissão de Política Urbana, Metropolitana e de MeioAmbiente e da Comissão de Educação, Cultura e Esportes da Câmara Municipal, bem como dois representantes de equipamentos culturais situados dentro dos limites do 
Parque, dois representantes de entidades culturais em geral, dois representantes de entidades ambientalistas, dois representantes de entidades ligadas ao esporte amador e ao lazer, um representante do Conselho Municipal de Turismo, um representante da Associação de Usuários e Amigos do Parque, um representante dos permissionários do uso do Parque, bem como até três representantes de outras entidades. Mesmo sem entrar mais profundamente na questão, não é demais mencionar a excessiva participação do poder público. A gestão dividida entre o setor público, privado e entidades sem fins lucrativos é o embrião daquilo que já foi definido por Dumazedier (1976) em seu livro mais inspirador e também o mais desconhecido.

Não que o lazer e a recreação tenham sido deixados de lado. Ao contrário, os novos parques contam com equipamentos como quadras poliesportivas e brinquedos, dentre inúmeros outros elementos, mas a aparente falta de comunicação e articulação entre a Secretaria do Verde e do Meio Ambiente (SVMA, que cria e administra os parques municipais) e a Secretaria de Esportes, Lazer e Recreação diz tudo. Não há qualquer menção a esta última em qualquer material referente aos parques urbanos de São Paulo. Mesmo as atividades existentes nos parques são todas coordenadas pela SVMA, o que parece um contrassenso.

\section{Considerações finais}

Procurou-se mostrar aqui a importância dos parques e as formas como o poder público e a sociedade vêm atuando em face das necessidades suscitadas. Hoje se trabalha com um cenário favorável à ampliação de parques urbanos. Eles pouco a pouco ganharam importância progressiva no planejamento urbano e disputam com os centros culturais, os grandes monumentos, etc. a condição de novas catedrais urbanas. 
Mas, em que pesem as recentes iniciativas para a implantação de parques urbanos na cidade de São Paulo, elas são insuficientes para reparar uma histórica negligência dos poderes públicos no provimento de áreas públicas de lazer.

Mesmo ao final do programa "100 parques para São Paulo", fica claro que a quantidade de parques municipais ainda será insuficiente para atender os mais de 11 milhões de moradores do município, pois alguns têm de se deslocar por muitos quilômetros para ter acesso a alguma dessas áreas.

O processo de periferização da população de São Paulo leva à necessidade de um novo paradigma no planejamento da construção de espaços públicos de lazer e recreação. Esse paradigma, na verdade, já deveria existir, pois a área do município é a mesma há pelo menos três décadas e nesse período já havia pessoas morando nos bairros mais distantes do centro. É histórica também a omissão da Prefeitura em fiscalizar os loteamentos e obrigar a prever e destinar áreas para o lazer e outras necessidades coletivas. A distribuição dos equipamentos de lazer públicos, com destaque para os parques urbanos, continua a ser feita nas áreas menos apetecíveis aos empreendedores imobiliários.

Somente uma política perene de proteção às áreas de mananciais, de regularização de loteamentos clandestinos, de ocupação racional dos espaços ainda pouco urbanizados e, principalmente, de estabelecimento de áreas verdes de lazer e recreação levará a este novo paradigma para os parques urbanos municipais na cidade de São Paulo e, assim, também contribuir para a redução da desigualdade social.

Pode-se dizer que a falta de áreas verdes públicas especialmente preparadas para o lazer dificulta a integração social e aumenta a sensação de distanciamento e segregação imposta aos moradores dos bairros periféricos de São Paulo, já que a 
necessidade de recreação simples não será reposta pelo lazer de consumo, pois esse também passa longe das áreas mais afastadas do centro.

Em longo prazo, em países ainda fortemente marcados por essa cultura tradicional, e, em curto prazo para as sociedades de urbanização mais consolidada, o panorama que se desenha é o de uma cidade que poderia ser chamada de verde. Uma cidade que, segundo Novarina (2003, p.15), "abole as fronteiras entre a cidade e o campo, em que os espaços naturais não estão mais situados fora da cidade, mas nos interstícios criados pela justaposição de formas urbanas".

Finalmente, lamente-se que as áreas verdes não sejam consideradas no mesmo nível de importância que as áreas azuis (espelhos d’água de tamanhos variados). O descaso com as represas, com os rios, lagos e córregos da cidade e com seu aproveitamento lúdico é tema que ainda nem entrou em pauta. Afinal, as atividades ao ar livre são as que mais crescem, seja na busca do contraponto sol/água (ou na fórmula mais ampla e completa dos anglo-saxões, o sex, sand and sea) seja em fórmulas que associam o prazer de estar em meio ao azul da água e do céu, associados a ambientes preservados. Fala-se aqui, em São Paulo, de um Tietê limpo e balneável como o Tâmisa em Londres e como o próprio Tietê o foi até o início do século XX. Será?

\section{REFERENCIAS}

BARTAlini, Vladimir. Parques públicos municipais de São Paulo. 1999. 324 f. Tese (Doutorado) - FAU/USP, São Paulo, 1999.

BOTELHO, Isaura. Os equipamentos culturais na cidade de São Paulo: um desafio para a gestão pública. Revista Espaço e Debates. São Paulo: NERU, v.23, n.43-44, jan/dez, 2003.

BRASIL. Constituição da República Federativa do Brasil (1988). Disponível em: <http://www.planalto.gov.br/ccivil_03/constituicao/constitui\%C3\%A7ao.htm>. Acesso em: 12 fev. 2011. 
CÂNDIDO, Antônio. Os parceiros do Rio Bonito. Rio de Janeiro: José Olympio, 1964.

CARTA DE ATENAS. Disponível em: $<$ http://pet.ecv.ufsc.br/download/Reuni\%F5es\%20culturais/Reuni\%F5es\%20em\%20PD F/CARTADEATENAS.pdf>. Acesso em: 15 dez. 2011.

CORONIO, Guy; MURET, Jean-Pierre. Loisirs: guide pratique dês équipements. Paris: CRU, 1976.

DUMAZEDIER, Joffre. Société educative et pouvoir culturel. Paris: Seuil, 1976

ELIAS, Norbert. O processo civilizador. Rio de Janeiro, Zahar, 1994.

FARIA, Ana Lúcia Goulart de. A contribuição dos parques infantis de Mário de Andrade para a construção de uma pedagogia da educação infantil. Educação e Sociedade, v. 20, n. 69, dez. 1999.

FLUSSER, Vilém. Fenomenologia do brasileiro. 1988 Disponível em: <http://textosdevilemflusser.blogspot.com>. Acesso em: 11 jan. 2012.

GOMES, Christianne Luce; MELO, Victor Andrade de. Lazer no Brasil: trajetória de estudos, possibilidades de pesquisa. Movimento, Porto Alegre, v. 9, n. 1, p. 23-44, jan./abr. 2003.

IBGE. Cidades@. Disponível em: <www.ibge.gov.br/cidadesat/painel/painel.php?codmun=355030\#>. Acesso em: $10 \mathrm{dez}$. 2010 .

KLIASS, Rosa Grená. Parques urbanos de São Paulo. São Paulo: Pini, 1993.

KOWARICK, Lúcio. Escritos urbanos. São Paulo: Editora 34, 2000.

MACEDO, Silvio Soares; SAKATA, Francine Gramacho. Parques urbanos no Brasil. São Paulo, Edusp, 2010.

NOVARINA, Gilles. Plan et projet: l'urbanisme en France et en Italie. Paris, Anthropos, 2003.

PANZINI, Franco. Per i piaceri del popolo: L'evoluzione del giardino pubblico in Europa dalle origini al XX secolo. Bologna: Zanichelli, 1993.

PRONOVOST, Gilles. Temps, culture et societé. Québec: Presses Universitaires du Québec, 1983.

SANTOS, Milton. Crescimento nacional e nova rede urbana: o exemplo do Brasil. Rio de Janeiro: Revista Brasileira de Geografia, v.29, n.4, 1967. 
SÃO PAULO (Município). Infocidade. Disponível em: < http://infocidade.prefeitura.sp.gov.br/htmls/7_populacao_recenseada_projetadataxas_de _c_1950_638.html>. Acesso em: 10 jan. 2011.

SÃO PAUlO (Município). Secretaria do Verde e do Meio Ambiente. Guia dos parques municipais de São Paulo volume 2. São Paulo: Prefeitura Municipal de São Paulo, 2010.

SÃO PAULO (Município). Secretaria Municipal do Desenvolvimento Urbano. Histórico demográfico do município de São Paulo. São Paulo, 2007. Disponível em: <http://smdu.prefeitura.sp.gov.br/historico_demografico/index.php>. Acesso em: 11 dez. 2010.

SÃO PAULO (Município). Mapa da Exclusão/Inclusão. 2002. Município em mapas. Disponível em: <http://www9.prefeitura.sp.gov.br/sempla/mm/mapas/intro_ei.pdf>. Acesso em: 10 nov. 2010.

SILVA, Júnior Vagner Pereira da; NUNES, Paulo Ricardo Martins. Parques públicos de lazer de interesse físico esportivo. Licere, Belo Horizonte, v.12, n.2, jun. 2009.

SCHREIBER, Yara. Domingo no parque: um estudo da relação homem-natureza na metrópole paulistana. 1997. 170 f. Dissertação (Mestrado). FFLCH-USP, São Paulo, 1997.

VIGARELLO, G. Histoire des pratiques de santé. Paris: Seuil, 1993.

WHATELY, Marussia et al. Parques urbanos municipais de São Paulo: subsídios para a gestão. São Paulo: Instituto Socioambiental, 2008.

\section{Endereço dos Autores:}

Brenno Vitorino Costa

Rua Padre Machado, 584, AP.84

CEP 04127-001 São Paulo - SP

Endereço Eletrônico: costabrenno@yahoo.com.br

Luiz Octávio de Lima Camargo

Rua Dr. Renato Paes de Barros, 56 - Ap.162

CEP 04530-000 - São Paulo - SP

Endereço Eletrônico: octacam@uol.com.br 